\title{
IMPLIKASI ORGANISASI MAHASISWA KESATUAN AKSI MAHASISWA MUSLIM INDONESIA (KAMMI) DALAM MEMBENTUK KARAKTER MELALUI DAURAH MARHALAH I
}

\author{
Ahmad Bustomi \\ IAIN Metro Lampung \\ , Email: $\underline{\text { ahmadbustomi@metrouniv.ac.id }}$
}

\begin{abstract}
The background of this research is the existency of extra campus organizations which have an ideology contradicting with Pancasila as the Nation Ideology and its democracy system which according to researcher it strongly threatens the integrity of Negara Kesatuan Republik Indonesia. On the other side, there are many news in various media which issues the confusions between Islamic Mission becoming the spirit of Islamic students organizations and the practice of some cadres in field such as fighting among islamic students and destroying campus or public fasilities. Absolutely recruitment curriculum is an important aspect to be analyzed more deeply considering from where it will be seen the direction of this students' movement working, the background and spirit of organizations. Therefore, the researcher focuses on something important to be analyzed especially related to the role of islamic student organization of extra campus on the forming of students' character of KAMMI cadre in UIN Sunan Kalijaga. The selection of organization around UIN Sunan Kalijaga is chosen because of the location in Yogyakarta, in which mostly becomes a place for the establishment of student organizations and UIN Sunan Kalijaga it self has a massive organization climate. This researchs are to describe the role of islamic student organization of extra campus in the forming of student characters by using a qualitative approach with the subject of research (informant) consisting of Leader, Secretary and Leader of Public Policy division. The metodes of data collection used are interview, observation, and documentation. Data analysis uses Milles Huberman model with data reduction technique, data presentation, and conclusion. The results of research show that: Firstly, The implementation of cadre curriculum KAMMI is as the method which has Guide in DAURAH MARHALAH called MC Instructor whose duty give introduction before presenter, guides the learning process in class and fgd/fanel companion, while the speakers is called the instructor. The method of study which consists of lecture method, question and answer, fgd/sgd, panel, group dinamics and debate. Second, the role of curriculum shows eight characters religious, tolerance, discipline, democratic, friendly/communicative, like to read, social care and responsible.
\end{abstract}

Keywords: KAMMI, DAURAH MARHALAH, Character Shaping.

\section{A. Pendahuluan}

Penelitian ini berangkat dari adanya organisasi mahasiswa Islam tertentu yang tidak sepakat dengan demokrasi yang diterapkan di 
Indonesia bahkan yang secara frontal ke \tidaksepakatannya terhadap pancasila sebagai dasar negara, teman-teman aktifis organisasi mahasiswa Islam yang golongan ini biasanya lebih mengamini dasar negara Indonesia menjadi Islam "tidak lagi pancasila", pancasila hanya dianggap sebagai suatu dasar negara yang tidak seharusnya dipakai, bid'ah, tidak sesuai dengan dasar negara yang diterapkan oleh Nabi dengan berdalih Indonesia yang mayoritas muslim, dimana para kader golongan ini menjustis bahwa Islam menjadi sebuah keniscayaan dijadikan sebagai dasar negara, bukan Pancasila yang sejatinya hal ini sangat mengancam keutuhan Negara Kesatuan Republik Indonesia. Disisi lain banyak berita di berbagai media yang memunculkan kerancuan-kerancuan antara misi Islam yang menjadi spirit organisasi mahasiswa Islam dengan implementasi para kaderya di lapangan seperti tauran yang dilakukan mahasiswa Islam, perusakan atau vandalism di lingkungan kampus atau fasilitas-fasilitas umum.

Kurikulum perkaderan menjadi hal yang paling pokok untuk dikaji lebih, mengingat dari sanalah akan terlihat arah gerakan mahasiswa ini berjalan, latar belakangnya serta spirit berorganisasinya. Oleh karena itu penting untuk dikaji terutama terkait perannya dalam pembentukkan karakter mahasiswa. Di samping pemaparan di atas, muncul pula fenomena-fenomena manarik mengenai kecenderungan-kecenderungan terkait adanya perubahan karakter yang terjadi pada mahasiswa selepas dari kegiatan pengkaderan, seperti: mulai pekanya mahasiswa terhadap fenomena sekitar terutama mengenai kebijakan-kebijakan yang terjadi di sekitarnya, baik kebjakan kampus, pemerintah bahkan kebijakan skop kecil seperti keputusan-keputusan dosen di kelas, perubahan dari yang tadinya tidak pernah solat berjamah menjadi mulai dan bahkan rajin jamaah pasca pengkaderan, ada yang mulai keranjingan baca buku bahkan adapula yang sebaliknya dalam arti melakukan tindakan-tindakan destruktif baik untuk dirinya sendiri maupun lingkungan, seperti muncul perilaku menyepelekan dosen, telat masuk kuliah, berpakaian kurang syar'i, over action dalam merespon kebijakan-kebijakan kampus seperti mencorat-coret dinding kampus, demo sampai memecahkan kaca kampus dan sebagainya, dengan demikian, ini berarti ada implikasi pada mahasiswa dalam proses pengkaderan sebelumnya tersebut. UIN Sunan Kalijaga dipilih menjadi kampus yang harus diteliti dikarenakan letaknya yang strategis yang mana di samping secara geografis berada di Yogyakarta yang menjadi kota pendidikan, disana pula menjamur organisasi secara massif. KAMMI yang merupakan salah satu organisasi yang eksistensinya tidak diragukan lagi dan menghegemoni di berbagai perguruan tingi menjadi penting untuk dikaji lebih dalam mengenai peran kurikulum pengkaderannya dalam membentuk karakter kader.

Tulisan ini hendak menjawab pertanyaan bagaimanakah implementasi kurikulum pengkaderan KAMMI dan bagaimanakah Implikasi kurikulum pengkaderan tersebut terhadap pembentukan 
karakter mahasiswa di UIN Sunan Kalijaga. Oleh karena itu, penelitian ini bertujuan untuk mendeskripsikan implementasi kurikulum pengkaderan KAMMI UIN Sunan Kalijaga. Serta mendeskripsikan implikasi kurikulum pengkaderan tersebut terhadap pembentukan karakter mahasiswa.

\section{Metode Penelitian}

Penelitian ini termasuk penelitian yang menggunakan pendekatan kualitatif dengan jenis penelitian lapangantif. Penelitian lapangan adalah studi tentang orang yang bertindak secara alamiah dalam kehdupan sehari-hari. Penelitian lapangan berusaha masuk ke dalam dunia orang lain untuk langsung memelajari mengenai kehidupan mereka, cara mereka berbicara dan berprilaku serta hal-hal yang menawan hati dan menggundahkan mereka. Penelitian ini juga terlihat sebagai metode Penelitian yang para praktisinya mencoba memahami makna dari berbagai kegiatan yang diamati bagi mereka yang terlibat di dalamnya". ${ }^{181}$ Metode penelitian kualitatif dapat diartikan sebagai metode penelitian yang berlandaskan pada filsafat postpositivisme/enterpretif, digunakan untuk meneliti pada kondisi obyek yang alamiah, ${ }^{182}$ (sebagai lawannya adalah eksperimen) dimana Penulis sebagai instrumen kunci, teknik pengumpulan data dilakukan secara trianggulasi (gabungan), analisis data bersifat induktif/kualitatif, dan hasil Penelitian kualitatif lebih menekankan makna daripada generalisasi. ${ }^{183}$ Subyek penelitian dalam penelitian kualitatif tidak menggunakan istilah populasi, tetapi oleh Spradley dinamakan sosial situation atau situasi sosial yang terdiri dari tiga elemen, yaitu tempat (place), pelaku (actor), dan aktifitas (activity) yang berinteraksi secara sinergis. Situasi sosial tersebut, dapat dinyatakan sebagai obyek penelitian yang ingin dipahami secara mendalam. Pada situasi sosial atau obyek penelitian ini penulis dapat mengamati secara mendalam aktifitas (activity), orang-orang (actors) yang ada pada tempat (place) tertentu. Sampel dalam penelitian kualitatif bukan dinamakan responden, tetapi sebagai narasumber, atau partisipan, informan, teman dalam penelitian. Sampel penelitian kualitatif juga bukan disebut sebagai sampel statistik tetapi sebagai sampel teoritis, karena tujuan penelitian kualitatif adalah untuk menghasilkan teori. ${ }^{184}$ Teknik sampling yang digunakan adalah purposive sampling, dan snowball sampling.Subjek penelitian ini adalah subjek yang dituju untuk diteliti ataudiharapkan informasinya mengenai hal-hal yang berkaitan denganmasalah yang diteliti. Dalam penelitian ini yang menjadi subjek adalah Ketua Umum,

181 W. Lawrence Neuman, Metodolog Penelitian Sosial: Pendekatan Kualitatif Dan Kuantitatif Karya, (Jakarta: Indeks, 2015), h. 461.

182 M. Kholis Amrullah and M. Irfan Islamy, Perencanaan Penelitian: Perjalanan Sistematis Penemuan Teori, ed. Ani Cahyadi (Malang: CV. Literasi Nusantara Abadi, 2020).

183 Sugiyono, Metode Penelitian Manajemen, (Bandung: Alfabeta, 2013), h. 347.

184 Sugiono, Metode Penelitian Pendidikan (Pendekatan Kuantitatif, Kualitatif Dan $R$ E D), (Bandung: Alfabeta, 2009), h. 15. 
Sekretaris Jenderal dan Ketua Bidang Kebijakan Publik KAMMI UIN Sunan Kalijaga. Metode pengumpulan data yang digunakan adalah observasi, wawancara dan studi dokumentasi. ${ }^{185}$ Teknik analisis data pada Penelitian ini menggunakan model Miles and Huberman yaituData reduction (reduksi data), Display data (penyajian data) dan Conclusion drawing/verification (penarikan kesimpulan).

\section{B. Pembahasan}

\section{Kurikulum Pengkaderan KAMMI}

Kurikulum pengkaderan adalah sejumlah materi pegkaderan dan kegiatan-kegiatan dan segala sesuatu yang berpengaruh terhadap pembentukkan pribadi kader sesuai dengan tujuan pengkaderan yang telah ditetapkan oleh organisasi. Sedangkan dalam istilah Saylor dan Alexander bila ditarik dalam dunia pengkaderan maka yang dimaksud kurikulum pengkaderan adalah merupakan keseluruhan usaha yang dilakukan oleh lembaga pendidikan (ORMAWA) utuk mencapai tujuan yang telah diharapkan. Dari hasil penelitian, penulis menemukan bahwa kurikulum pengkaderan KAMMI setidak-tidaknya terdiri dari:

1. Tujuan

Tujuan DAURAH MARHALAH 1 adalah Memperkenalkan KAMMI kepada para peserta DAURAH MARHALAH 1 agar mereka mengenal dan paham tentang KAMMI.

2. Isi

Materi wajib DAURAH MARHALAH I terdiri dari syahadatain sebagai titik tolak perubahan, syummuliatul-islam (kesempurnaan islam), problemtika ummat kontemporer, manajemen aksi dan sejarah KAMMI. ${ }^{186}$

\section{Evaluasi}

Evaluasi terdiri dari evaluasi harian dan evaluasi keseluruhan.

Jika kurikulum adalah programnya, maka pembelajaran merupakan implementasinya. Jika kurikulum adalah teorinya, maka pembelajaran adalah praktiknya. Oleh karena penjelasan tersebut, maka dapat dijelaskan bahwa implementasi kurikulum pengkaderan berada pada pelatihannya, karena dari sana letak pembelajaran berlangsung dalam KAMMI. Pembelajaran atau dalam bahasa pengkaderan disebut dengan pelatihan memiliki berbagai cara/metode dengan keunggulan dan kekurangannya masing-masing. Adapun yang dimaksud dengan metode pembelajan adalah cara yang digunakan guru untuk menyampaikan pelajaran kepada siswa. ${ }^{187}$ Berkenaan dengan implementasi, maka

\footnotetext{
185 Ahmad Tanzeh, Metodologi Penelitian Praktis, (Yogyakarta: Teras, 2011), h. 167.

186 Wawancara pada tanggal 24 November 2018.

187 Hamdani, Strategi Belajar Mengajar , (Bandung: Pustaka Stia, 2011), h. 80.
} 
implementasi yang dimaksudkan adalah implementasi dalam bentuk pelatihan dan penugasan.

1. Pelatihan (DAURAH MARHALAH)

Pemandu dalam DAURAH MARHALAH disebut instruktur MC, bertugas memberikan pengantar sebelum pemateri memberi materi, memandu jalannya kelas dan pendamping fgd/panel, sedangkan pemateri disebut instruktur. Metode belajar dalam pelatihan (DAURAH MARHALAH) menggunakan metode ceramah, tanya jawab, fgd/sgd, panel, dinamika grup dan debat.

2. Penugasan

Pendelegasian/penugasan sebagaimana organisasi mahasiswa Islam ekstra kampus pada umumnya, merupakan salah satu bentuk dari tindak lanjut pelatihan dasar termasuk juga berlaku di KAMMI baik itu dalam bentuk peugasan maupun penelegasian dalam struktural kampus yang kompetitif maupun semi kompetitif.

\section{Implikasi DAURAH MARHALAH I KAMMI Dalam Pembentukkan Karakter}

Berdasarkan analisis yang dilakukan penulis maka ditemukan beberapa karakter yang menjadi implikasi dari perkaderan di KAMMI yaitu:

1. Religius

Sedikit mengulas tentang relgius yakni sikap dan prilaku yang patuh dalam melaksanakan ajaran agama yang dianutnya, toleran terhadap pelaksanaan ibadah agama lain, dan hidup rukun dengan pemeluk agama lain. KAMMI sangat menekankan kadernya agar senantiasa patuh menjalankan ajaran agama, maka tidak heran jika materi utama dari KAMMI adalah Aqidah dan Syummuliyatul Islam bahkan panitia DAURAH MARHALAH 1 sudah menyediakan waktu khusus untuk solat ditengah padatnya jadwal DAURAH MARHALAH sebagaimana disampaikan oleh Dhika bahwa:

“Abis itu pembukaan sebentar, abis itu lagi siap-siap sholat. Nanti abis itu makan, abis isya, abis sholat isya baru mulai materi pertama sampai selesai". ${ }^{188}$

Prilaku senantiasa menjalankan perintah agama ini sengaja tidak hanya terlihat dari pengalokasian waktu tentunya, akan tetapi juga dengn solat berjamaah pada saat DAURAH MARHALAH 1 berlangsung. Lebih jauh muatan religius ini tidak hanya disampaikan oleh Dhika sebatas pencitraan saja melainkan juga penulis saksikan sendiri bahwa ketika penulis mendatangi sekretariat KAMMI, banyak dari anggota (penghuni sekretariat) yang baru saja melaksanakan solat isya berjamaah di Masjid.

2. Toleransi

188 Wawancara pada tanggal 24 November 2018. 
Sedikit mengulas kembali mengenai toleransi yakni Sikap dan tindakan yang menghargai perbedaan agama, suku, etnis, pendapat, sikap, dan tindakan orang lain yang berbeda dari dirinya. KAMMI sebagai salah satu organisasi mahasiswa Islam yang memiliki kader dengan jumlah besar meski bisa dikatakan lahir paling belakangan termasuk organisasi yang mengedepankan muatan toleransi mulai dari budaya perkaderannya sebagai gerbang pintu awal kader mengenal KAMMI. Hal tersebut diantaranya terlihat ketika metode pembeajaran digambarkan oleh Dhika bahwa:

"Nanti dipantik dulu yah mas yah. Dikasih materi, pemateri juga mancingmancing materi, biar ada yang apa namanya, syukur-syukur ada yang ngajak debat atau gimana."189

Adanya upaya dari pemateri dan instruktur yang menstimulusi peserta DAURAH MARHALAH 1 menunjukkan bahwa kader dipupuk perasaan dan jiwa persamaan antara dirinya dan pemateri/instruktur, tidak ada pengkultusan terhadap pemateri/instruktur bahwa mereka yang mutlak benar dan peserta dianggap kertas kosong yang belum mengerti aa-apa. Peserta juga diberi stimulus agar senantiasa menghargai perbedaan yang sering muncul antara dirinya dengan pesera lain dan atau pebedaan pandangan dengan pemateri sekalipun. Lebih jauh hal ini juga menunjukkan bahwa kader senior KAMMI dalam hal ini pemateri dan instruktur menghargai perbedaan pendapat orang lain yang berbeda dengan dirinya karena pintu debat dibuka selebar-lebarnya dalam kelas DAURAH MARHALAH 1. Lebih jauh mengenai sikap toleran kader KAMMI sangat nampak juga ketika Haidar memaparkan terkait sistem magang bahwa:

"Iya disesuaikan dengan minat dan bakat mereka. Jadi nanti mereka dikasi form untuk diisi. Jadi mereka minatnya dimana, bakatnya apa dan maunya dimana, nanti dimasukin ke bidang tertentu yang mereka sukai dan sesuai dengan minat dan bakat mereka. Misal mereka suka jurnalistik mereka dimasukin ke humas." 190

KAMMI setelah melakukan kegiatan DAURAH MARHALAH 1 selain mengadakan follow up terkait pendalaman materi, disana juga mengagendakan magang. Magang bisa diartikan sebagai suatu kegiatan beajar mengenai bidang dalam kepengurusan KAMMI dengan disesuaikan minat bakat kader berdasarkan hasil penelitian yang mana biasanya didapatkan melalui form yang diisi oleh kader baru. Proses tersebut menunjukkan begitu tolerannya kader kami terhadap kemampuan/minat bakat kader baru dalam mengarahkan kesetiap bidang yag ada dalam KAMMI, jadi tidak ada prilaku acuh terhadap perbedaan yang dimiliki kader dalam magang ini. Pengklasifikasian seperti ini yang selain menjadi solusi perbedaan serta menunjukkan

189 Wawancara pada tanggal 24 November 2018.

190 Wawancara pada tanggal 06 Februari 2018. 
adanya prilaku toleran, hal ini jugajalan keluar ketika dihadapkan adanya perbedaan kecenderungan sumber daya sehingga hal ini dapat memaksimalkan sumber daya manusia yang ada pada diri KAMMI itu sendiri.

\section{Disiplin}

Sebagaimana sudah dijelaskan sebelumnya bahwa disiplin disini adalah tindakan yang menunjukkan prilaku tertib dan patuh pada berbagai ketentuan dan peraturan. KAMMI semenjak DAURAH MARHALAH 1 sudah menyambut kader barunya dengan kedisiplinan dengan memberikan jadwal kegiatan yang padat, bahkan berkenaan terkait jadwal solat, makan dan jadwal istiahat. Kemudian memberikan serentetan proses yang dilalui kader setelah melalui DAURAH MARHALAH 1 yaitu follow up yang kemudian dilanjutkan dengan magang yang mana dengan hal tersebut tidak hanya mematangkan jiwa organisasinya secara teknis akan tetapi juga kedisiplinan kader hingga terbiasa melalui jalan sebagaimana aturan yag berlaku. Tidak heran kader sudah sanggup mejalankan peran fungsinya masing-masing sesuai dengan pembagian di awal bahkan ketika harus evaluasi sebuah kepanitiaan di malam yang larut sekalipun. Kader KAMMI juga dalam melaksanakan agendanya sangat tidak mungkin untuk keluar jalur, karena jika keluar jalur, maka secara otomatis akan saling tumpang tindih dan terjadi gesekan-gesekan baik dalam internal maupun eksternal yang akan mempengaruhi roda oranisasi misalkan saja dalam isi penyampaian Dhika terkait alur pengkaderan bahwa:

"Pokoknya setiap komisariat itu kan, untuk mengadakan dauroh itukan harus laporan dulu ke KAMMI Wilayah, kemudian setelah diizinkan atau di iya kan, nanti waktunya kapan itu nunggu dari keputusan wilyah dulu kemudian nanti dari wilayah itu akan memberikan istruktur-instruktur untuk dipelajari, jadi bukan kita yang nyari tapi mereka yang langsung ngasih."191

Pemaparan Dhika tersebut dapat penulis simpulkan pola prilaku tertib pada aturan yang berlaku pada diri KAMMI, yang mana sebenarnya ini berimbas pada keselarasan/kebaikan sendiri pada perkaderan kalau dilihat pada pemaparan di atas.

\section{Demokratis}

Demokratis yang merupakan cara berfikir, bersikap dan bertindak yang menilai sama hak dan kewajiban dirinya dan orang lain senantiasa dipupuk pada diri KAMMI karena itu menjadi salah satu modal dasar, maka tidak heran semua kader di DAURAH MARHALAH 1 yang merupakan pintu masuk megenal KAMMI kader senantiasa dikondisikan untuk akrab dan mengendap dalam dirinya untuk senantiasa berfikir dan bertindak menganggap sama dirinya dan orang lain seperti upaya-upaya yang dilakukan pemateri maupun instruktur yang menstimulusi kader

191 Wawancara pada tanggal 24 November 2018. 
baru agar ikut memberikan kontribusi pemikirannya tidak lain merupakan salah satu bentuk agar kader baru mengaggap dirinya sama dengan pemateri dan sama juga dengan peserta lain yang memiliki hak berbicara. Hal tersebut juga menandakan kader senior mengakui persamaan antara dirinya dengan kader baru dalam forum kelas bahkan lebih jauh hendak menularkan jiwa demokratistersebut pada diri kader baru.

5. Bersahabat/komunikatif

Sebagaimana sudah dijelaskan sebelumnya bahwa bersahabat disisni adalah tindakan yang menunjukkan rasa senang berbicara, bergaul dan bekerja sama dengan orang lain.KAMMI selaku organisasi yang mapan tentunya tidak bisa lepas dari komunikasi yang massif, karena akan banyak terjadi permasalahan jika prilaku bersahabat/komunikatif ini tidak berjalan sebagaimana baiknya. Oleh karena itu tidak heran jika sejak DAURAH MARHALAH 1 kader baru sudah diberi stimulus untuk senantiasa mengungkapkan gagasan-gagasannya sebagai percikanpercikan awal rasa senang berinteraksi dengan orag lain dan cakap berbicara terutama di muka umum yang setidak-tidaknya dialog dengan pemateri atau instruktur. Prilaku tersebut juga menggambarkan bahwa senior (pemateri dan instruktur) juga senang menyambung komunikasi dengan kader baru. Maka tidakheran juga jika ketika kader terbiasa saling menjalin komunikasi yang baik entah itu antara kader, antar pengurus bahkan hingga tingkat cabang atau pusat seperti jawaban Dhika berkaitan dengan teknis perkaderan bahwa:

"Pokoknya setiap komisariat itu kan, untuk mengadakan dauroh itukan harus laporan dulu ke KAMMI Wilayah, kemudian setelah diizinkan atau di iya kan, nanti waktunya kapan itu nunggu dari keputusan wilyah dulu kemudian nanti dari wilayah itu akan memberikan istruktur-instruktur untuk di pelajari, jadi bukan kita yang nyari tapi mereka yang langsung ngasih."192

Dari pemaparan Dhika di tas menunjukkan adanya prilaku komunikasi/kerjasama yang baik antara pengurus tingkat komisariat dengan yang di daerah yang mana hal tersebut memberi kejelasan tentang suatu bentuk komunikasi yang baik di dalam diri kader KAMMI, bahkan dari pemaparan tersebut juga terlihat ada komunikasi timbal balik dari atas yang dalam hal ini KAMMI wilayah jogja mengenai izin waktu pelaksanaan, instruktur yang akan dikirim hingga pemateri DAURAH MARHALAH 1.

\section{Gemar Membaca}

Gemar membaca sebagaimana sudah dipaparkan dalam BAB 1 yaitu kebiasaan untuk menyediakan waktu untuk membaca berbagai bacaan yag memberikan kebajikan bagi dirinya. KAMMI sangat mendrong kadernya untuk senantiasa membiasakan diri untuk gemar membaca

192 Wawancara pada tanggal 24 November 2018. 
buku maka tidak heran jika pasca DAURAH MARHALAH 1 hal yang dilakukan pertama-tama adalah memberikan stimulus kader baru dengan mendapatkan jatah membaca buku dengan secara bergilir mempresentasikan buku hasil bacaannya di dalam forum lingkar kecil kader baru tersebut. Hal ini sebagaimana yang disampaikan Haidar bahwa:

"Jadi nanti di follow up itu Madrasah KAMMInya itu, jadi selain ditugaskan membaca buku wajib dia juga ada Madrasah KAMMI Klasikal."193

Lebih jauh mengenai tindak lanjut dari penugasan kader baru untuk membaca buku sebagaimana yang disampaikan oleh Khaidar adalah: "Jadi, itu seangkatan kumpul, membedah buku tersebut, didikusikan, nanti presentasi bergilir begitu."194

Hal ini tentu saja para senior (pengurus maupun demisioner) sudah menguasai terlebih dahulu, membaca terlebih dahulu bahkan harus lebih memiliki wacana yang lebih luas setidak-tidanya terkait buku yang akan dikupas oleh kader baru, karena merekalah yang akan menjadi inspirasi sekaligus pengarah jika apa yang disampaikan kader baru megalami kekeliruan atau melenceng dari pembahasan yang ada pada buku tersebut.

\section{Peduli sosial}

Peduli sosial yang dimaksud disini adalah sikap dan tindakan yang ingin selalu memberi bantuan pada orang lain dan masyarakat yang membutuhkan. KAMMI dalam hal ini sangat mendorong kadernya untuk memupuk karakter peduli sosial, maka tidak heran jika materi problematika umat kontemporer menjadi salah satu materi wajib. Mulai dari hal kecil seperti dalam forum-forum evaluasi, kader sudah mulai mengasah sikap dan pemikiran untuk saling peduli terhadap rekannya entah dalam memberi masukan maupun dalam mengkritik karena bagaimanapun juga itu untuk kebaikan rekan secara khusus ataupun bidang/divisi secara struktural maupun untuk kebaikan KAMMI secara umum. Tidak hanya sebatas itu, dalam hal pemilahan kader baru ketika magang, Rizki menyampaikan bahwa:

"Kita sebelum masukin, kita tanya dulu, sebar questioner dulu. Jadi kita sesuaikan dengan apa yang mereka minatkan."195

Dalam hal pembagian tempat magang kader baru ke dalam berbagai divisipun kader KAMMI turut serta mengamati dan mengarahkan kader baru agar tidak terjadi salah sasaran dan tidak maksimalnya proses magang yang berlangsung baik melalui pengamatan langsung maupun lewat quesioner. Hal ini menunjukkan adanya upaya membantu kader baru bukan lepas tangan begitu saja ketika kader sudah resmi melewati proses DAURAH MARHALAH 1.

\footnotetext{
193 Wawancara pada tanggal 06 Februari 2018.

194 Ibid.,

195 Wawancara pada tanggal 31 Januari 2018.
} 
8. Tanggung Jawab

Tanggung jawab adalah sikap dan perilaku seseorang untuk melaksanakan tugas dan kewajibannya yang seharusnya dia lakukan, terhadap diri sendiri, masyarakat, lingkungan (alam, sosial dan budaya), Negara dan Tuhan YME. Sebagaimana sudah dipaparkan sebelumnya terkait adanya bantuan senior (panitia/pengurus) ketika kader baru magang menunjukkan adanya bentuk tanggung jawab mereka terhadap kader baru, tidak serta merta ketika kader baru sudah resmi menjadi anggota KAMMI lantas dilepas begitu saja tanpa sedikitpun arahan dari seniornya.

\section{Kesimpulan}

Pemandu dalam DAURAH MARHALAH disebut instruktur MC, yang memiliki tugas memberikan pengantar sebelum pemateri memberi materi, memandu jalannya kelas dan pendamping fgd/panel, sedangkan pemateri disebut instruktur. Metode belajar dalam pelatihan (DAURAH MARHALAH) menggunakan metode ceramah, tanya jawab, fgd/sgd, panel, dinamika grup dan debat. Implikasi kurikulum telah membentuk 8 karakter, yaitu karakter religius, toleransi, disiplin, demokaratis, bersahabat/komunikatif, gemar membaca, peduli sosial dan tanggung jawab.

\section{Referensi}

Amrullah, M. Kholis, and M. Irfan Islamy. Perencanaan Penelitian: Perjalanan Sistematis Penemuan Teori. Edited by Ani Cahyadi. Malang: CV. Literasi Nusantara Abadi, 2020.

Hamdani, Strategi Belajar Mengajar, Bandung: Pustaka Setia, 2011.

Hamalik, Oemar, Perencanaan Pengajaran Berasarkan Pendekaan Sistem, Jakarta: Bumi Aksara, 2011.

Neuman, W. Lawrence, Metodolog Penelitian Sosial: Pendekatan Kualitatif dan Kuantitatif, Jakarta: Indeks, 2015.

Sugiyono, Metode Penelitian Manajemen, Bandung: Alfabeta, 2013. Metode Penelitian Pendidikan (Pendekatan Kuantitatif, Kualitatif Dan $R$ \& D), Bandung: Alfabeta, 2009.

Suparlan, Tanya Jawab Pengembangan Kurikulum \& Materi Pembelajaran, Jakarta: Bumi Aksara, 2012.

Tanzeh, Ahmad, Metodologi Penelitian Praktis, Yogyakarta: Teras, 2011. Wibowo, Agus, Pendidikan Karakter Strategi Membangun Karakter Bangsa Berperadaban, Yogyakarta: Pustaka Pelajar, 2012.

Zubaedi, Desain Pendidikan Karakter "Konsepsi dan Aplikasinya dalam Lembaga Pendidikan", Jakarta: Kencana Prenada Media Group, 2012. 